\title{
School Leaders' Emotional Experiences and Capabilities: Perspectives, Challenges, and Prospects
}

\author{
Junjun Chen $^{1} \cdot$ Izhak Berkovich $^{2} \cdot$ Ori Eyal $^{3}$
}

Published online: 23 March 2021

(C) De La Salle University 2021

School leaders are being increasingly held accountable for implementing unremitting changes that have been adopted by policymakers at higher levels of the education system. Leading change has been described as an emotionally complex facet of leadership behaviour (James et al., 2019). These emotionally hot climates have the effect of decreasing decision-making latitude and autonomy, which leads to 'scrutiny stress' (Maxwell \& Riley, 2017). It has been pointed out that principals and educational managers nowadays have to juggle many sensitive demands such as the needs of relevant stakeholders, competing objectives, tricky stakeholder interactions, the impression others have of them, and teachers' emotions (Berkovich \& Eyal, 2015, 2020a; Chen, 2020). It is especially true in the current COVID-19 pandemic in which school leaders' professional life has been dramatically changed. All of these are emotionally draining for principals and educational managers, placing increased pressure on them to act as 'emotional leaders' (Berkovich \& Eyal, 2020b; Bush, 2018). This situation harms the psychosocial and physiological health of school leaders, reciprocally affecting job performance and satisfaction (De Nobile \& McCormick,

Izhak Berkovich

izhakber@gmail.com

$\bowtie$ Ori Eyal

ori.eyal1@mail.huji.ac.il

Junjun Chen

jjchen@eduhk.hk

1 The Education University of Hong Kong, Ting Kok, Hong Kong

2 The Open University of Israel, Ra'anana, Israel

3 The Hebrew University of Jerusalem, Jerusalem, Israel
2010). Therefore, school leaders' emotions and their emotional capabilities increasingly become one of the key aspects in taking a school forward (Chen \& Guo, 2020; Chen \& Walker, 2021; Leithwood et al., 2020).

Although the significance of school leaders' emotions and emotional capabilities in various aspects of education has been recognised, research on educational leaders has placed continuous emphasis on rationality, and underplayed the emotive aspect for quite a long time (Berkovich \& Eyal, 2017, 2020b). It is becoming apparent that school leaders are ill-prepared and insufficiently supported by preparation and induction programmes in how to regulate their own emotional aspects and those of related stakeholders (Chen, 2021; Zembylas, 2018).

Inspired by the affective paradigm for education leadership theory (see Berkovich \& Eyal, 2020b) and practice connecting affect, actions, and power (see James et al., 2019), we focussed in this special issue on school leaders' emotions and emotional capabilities to draw the attention of education scholars, policymakers, and practitioners to the significance of this topic. The works in this special issue examine how principals' emotions and emotional capabilities shape leading, teaching, and school effectiveness. This special issue brings theoretical and practical insights to the knowledge base of school leaders' emotions and emotional capabilities research. In doing so, we hope to advance our understanding of the nature of school leaders' emotional experiences and capabilities, and of the role that individual, organisational, and contextual factors play in influencing them in educational settings.

The special issue includes five papers that are sampled from Hong Kong, China, Israel, and the United States. There are three qualitative papers and two quantitative papers across kindergartens and secondary schools. The first paper is by To and Yin (2021) which investigated how kindergarten principals in Hong Kong utilised emotion 
regulation strategies to fulfil their leading roles. Five principals linked their emotions to the psychosocial climate of the kindergartens, highlighting that emotion regulation is essential for the flourishing of the kindergartens. These principals also reported employing interpersonal emotion regulation strategies to facilitate their emotion regulation through social interactions. Taken together, these strategies contributed to the emotional well-being of the principals, thus, optimising their interactions with teachers and parents so that the children would also benefit.

The second paper by Qian and Walker (2021) aimed to explore how principals build reciprocal relationships with teachers via the display and enactment of paternalistic leadership using a large sample of 101 primary school principals from six provinces in China. These principals reported adopting a paternal leadership approach where they provided protection and care for teachers while maintaining high expectations of quality teaching. The principals managed to win trust from teachers, which appeared to signify a strong personal bond founded on positive emotions.

By focussing on the crisis situation from the United States, the third paper by Mahfouz et al., (2021) examines the role of emotions in educational leadership through a case study analysis of an assistant superintendent who successfully used emotional awareness to confront challenges and facilitate positive change. The findings, which reveal the effective use of emotional responses to promote positive organisational change, provide guidance for educational leadership preparatory programmes which must cultivate future leaders' emotional regulation skills. This study addresses a notable gap in the literature by examining a leader's effective employment of self-awareness, emotional management, and emotional impact for meaningmaking to navigate organisational change.

The fourth paper by Berkovich and Eyal (2021) explored the effect of different profiles of emotional feedback in principal-teacher relations on followers' perceptions of the leader on attributed charisma and leadermember exchange (LMX) using a survey of 645 teachers from public primary schools in Israel. The findings indicate four profiles of emotional feedback from principals, namely, profile 1 on positive emphasis, profile 2 on mixed feedback, profile 3 on non-manipulative, and profile 4 on negative emphasis. The study also showed that as long as there is positive feedback, even if it is accompanied by a negative one, the followers' perceptions of the leader are positive.

The final paper by Cheng et al., (2021) investigated teacher leaders' emotions and their relationship with teacher professionalism and collegial trust using a sample of 477 teacher leaders from primary and secondary schools in China. This study found that positive emotions (e.g. pride and love) from teacher leaders positively and significantly affected their trust in colleagues. Moreover, enjoyment was positively affected, and fatigue and anxiety negatively affected teacher professionalism. It is also interesting to note that pride negatively affected teacher professionalism through collegial trust.

To sum up, the papers in this special issue provide an important portrait of the complex nature of school leaders' emotions and how these affect other critical aspects of schooling. This special issue justly epitomises a mix of data sources and viewpoints concerning school leaders' emotional experience. We sincerely wish that the contributions from this special issue will stimulate scientific academic and educational work on this theme in the future, and encourage as well as serve practitioners and policymakers.

\section{References}

Berkovich, I., \& Eyal, O. (2015). Educational leaders and emotions: An international review of empirical evidence 1992-2012. Review of Educational Research, 58(1), 129-167.

Berkovich, I., \& Eyal, O. (2017). Good cop, bad cop: Exploring school principals' emotionally manipulative behaviours. Educational Management Administration \& Leadership, 45(6), 944-958.

Berkovich, I., \& Eyal, O. (2020a). School leaders' emotional support of teachers through emotional transformation: Qualitative insights into the maintenance of teachers' occupational identity. Leadership and Policy in Schools, 19(4), 625-639.

Berkovich, I., \& Eyal, O. (2020b). A model of emotional leadership in schools: Effective leadership to support teachers' emotional wellness. Routledge.

Berkovich, I., \& Eyal, O. (2021). Profiles of emotional feedback and their effect on principal's attributed charisma and leadermember exchange quality (LMX). The Asia-Pacific Education Researcher. https://doi.org/10.1007/s40299-021-00552-2.

Bush, T. (2018). Preparation and induction for school principals: Global perspectives. Management in Education, 32(2), 66-71.

Chen, J. (2020). Development and validation of the Principal Emotion Inventory: A mixed-method approach. Educational Management Administration \& Leadership. https://doi.org/10.1177/174 1143220919764.

Chen, J. (2021). School principals' emotional labor strategies: A narrative perspective. In J. Chen \& R. R. King (Eds.), Emotions in learning, teaching, and leadership: Asian perspectives (pp. 198-211). Routledge.

Chen, J., \& Guo, W. (2020). Emotional intelligence can make a difference: The role of principals' emotional intelligence on teaching strategy mediated by principals' instructional leadership. Educational Management Administration \& Leadership, 48(1), 82-105. https://doi.org/10.1177/1741143218781066.

Chen, J., \& Walker, A. (2021). Emotional trajectory at different principalship career stages: A perspective from excellent principals. Educational Management Administration \& Leadership. https://doi.org/10.1177/1741143220985300.

Cheng, T. J., Chen, J., \& Bryant D. (2021). Teacher leaders' emotions mirror teacher professionalism via collegial trust. The Asia- 
Pacific Education Researcher. https://doi.org/10.1007/s40299-021-00551-3.

De Nobile, J. J., \& McCormick, J. (2010). Occupational stress of Catholic primary school staff: A study of biographical differences. International Journal of Educational Management, 24(6), 492-506.

James, C., Crawford, C., \& Oplatka, I. (2019). An affective paradigm for educational leadership theory and practice: connecting affect, actions, power and influence. International Journal of Leadership in Education, 22(5), 617-628.

Leithwood, K., Harris, A., \& Hopkins, D. (2020). Seven strong claims about successful school leadership revisited. School Leadership \& Management, 40(1), 5-22.

Mahfouz, J., King, K., \& James, L. D. (2021). Lessons from the storm: Emotions, meaning-making and leadership during transition. The Asia-Pacific Education Researcher.

Maxwell, A., \& Riley, P. (2017). Emotional demands, emotional labour and occupational outcomes in school principals:
Modelling the relationships. Educational Management Administration \& Leadership, 45(3), 484-502. https://doi.org/ $10.1177 / 1741143215607878$.

Qian, H., \& Walker, A. (2021). Building emotional principal-teacher relationships in Chinese schools reflecting on paternalistic leadership. The Asia-Pacific Education Researcher.

To, K. H., \& Yin, H. B. (2021). Being the weather gauge of mood: Demystifying the emotion regulation of kindergarten principals. The Asia-Pacific Education Researcher. https://doi.org/ 10.1007/s40299-021-00559-9.

Zembylas, M. (2018). Professional standards for teachers and school leaders: Interrogating the entanglement of affect and biopower in standardizing processes. Journal of Professional Capital and Community, 3(3), 142-156.

Publisher's Note Springer Nature remains neutral with regard to jurisdictional claims in published maps and institutional affiliations. 